(c) 2013 The Author(s) Journal of Eukaryotic Microbiology (

2013 International Society of Protistologists

The definitive version is available at http://onlinelibrary.wiley.com/

\title{
Heat Shock Protein 90 of Bonamia ostreae: Characterization and Possible Correlation with Infection of the Flat Oyster, Ostrea edulis
}

\author{
Maria Prado-Alvarez, Bruno Chollet, Yann Couraleau, Benjamin Morga, Isabelle Arzul ${ }^{\star}$
}

IFREMER, Laboratoire de Génétique et Pathologie, La Tremblade, France

*: Corresponding author : Isabelle Arzul, Tel.: (33) 546762610 ; fax : (33) 546762611 ; email address : iarzul@ifremer.fr

\begin{abstract}
:
In this study, we described the cytosolic HSP90 of Bonamia ostreae, an intracellular parasite of Ostrea edulis hemocytes. The complete open reading frame was assembled by Rapid Amplification cDNA Ends reactions on cDNA of $B$. ostreae-infected hemocytes. HSP90 amplification was corroborated in infected oysters and B. ostreae purified cells. The functionality of the HSP90, studied by inhibitory assays with radicicol, suggests that this protein may play a role in hemocyte invasion. Our results inform the molecular basis that governs $B$. ostreae-O. edulis interactions.
\end{abstract}

Keywords : Bivalve hemocytes ; Gene ; Haplosporidia ; Pathogen ; Protist ; radicicol 
Bonamia ostreae (Haplosporidia) is a parasitic protist that has caused important oyster production losses during last decades (Pichot et al. 1979). Its natural host is the European flat oyster Ostrea edulis and it has been reported in Europe and in the East coast of North America (Bucke et al. 1984; Elston et al. 1986; McArdle et al. 1991; Montes 1990; Narcisi et al. 2010; Van Banning 1985). Bonamia ostreae parasitizes larvae, seeds, juveniles and adult organisms. However oysters older than 2 years are more susceptible to the infection (Arzul et al. 2011; Cáceres-Martínez et al. 1983; Culloty and Mulcahy 1996). Although B. ostreae is considered an intrahaemocytic parasite it can be found extracellularly on gills and in connective tissue (Comps et al. 1980; Montes et al. 1994; Van Banning 1990). The complete life cycle of the parasite is not known. However, it seems that intermediate hosts are not needed since infected oysters can transmit the disease to healthy organisms under experimental conditions (Elston et al. 1986). One of the main inconveniences in the study of this parasite is the absence of optimal conditions for maintaining an in vitro cell culture. To date, $B$. ostreae cells can only be obtained by a process of purification from heavily infected oysters (Mialhe et al. 1988). Purified B. ostreae has been used to study its effect on the immune system of the oyster $O$. edulis. Both in vitro contact with haemocytes and inoculation to healthy oysters revealed that the parasite modifies the immune status of the host to induce the up-regulation of immune related genes and the activation of cellular parameters (Comesaña et al. 2012; Morga et al. 2009; Morga et al. 2011a, b). However, the process of infection and the parasite mechanisms to evade host defenses still remain unclear. Although parasite genomic data could help to better understand these mechanisms, genomes of Haplosporidia are poorly documented. Actin is currently the typical functional gene described in these protists that has been used in phylogenetic 
studies (Burki et al. 2010; López-Flores et al. 2007). Among protists that parasitize vertebrates, the heat shock protein 90 (HSP90) has been one of those most commonly studied. HSP90 is a molecular chaperone involved in numerous biological processes including folding and stabilization of many proteins such as kinases, transcription factors and signalling molecules (Hahn 2009; Pratt and Toft 2003; Yahara 1998).

From an evolutionary point of view, heat shock proteins are considered very useful in phylogenetic studies because they are conserved throughout prokaryotes and eukaryotes (Chen et al. 2006; Fast et al. 2002). Higher eukaryotes have two cytosolic HSP90 isoforms that are inducible, and three organelle-specific HSP90 in chloroplasts, mitochondria and the endoplasmic reticulum. Parasite HSP90 proteins are involved in the development of infective stages and cell invasion by Leishmania, Plasmodium, Toxoplasma and Eimeria (Ahn et al. 2003; Banumathy et al. 2003; Echeverria et al. 2005; Péroval et al. 2006; Wiesgigl and Clos 2001). Due to its involvement in infective processes, HSP90 has been proposed as a good target for therapy (Neckers and Tatu 2008).

In the present work, the complete B. ostreae HSP90 gene has been amplified and characterized from the cDNA of infected O. edulis haemocytes. HSP90 detection has been tested in a set of infected and non-infected samples as well as in purified parasites. The involvement of this protein in the infection process of $O$. edulis haemocytes has also been investigated through in vitro experiments.

\section{MATERIALS AND METHODS}

Animals and haemolymph. Ostrea edulis oysters were collected in Quiberon Bay (Southern Brittany, France) and maintained in quarantine facilities consisting of an open circuit with 1- $\mu$ m filtered sea water (FSW) supplemented with Skeletonema costatum, Isochrisis galbana, Chaetoceros gracialis and Tetraselmis suecica. 
Haemolymph was withdrawn using sterile syringes and needles after drilling a hole in the valve. Individual haemolymph samples were filtered through a mesh of $75 \mu \mathrm{m}$ and maintained on ice to avoid cell aggregation. Cell counts were performed using a Malassez chamber.

Parasite purification. Infected oysters were selected after light microscopic visualization of $B$. ostreae in heart imprints. The degree of infection was assigned as described before (Robert et al. 2009). Parasites were purified from highly infected oysters following Mialhe et al. (1988) with slight modifications: the 40\%-20\% sucrose gradient was replaced by one of $60 \%-20 \%$, and the Percoll gradient step was removed. Purified parasites were suspended in 0.22- $\mu \mathrm{m}$ FSW and counted on Malassez chamber.

Rapid Amplification of cDNA Ends (RACE). Expressed Sequence Tags (ESTs) with high similarity to parasite genes were previously identified in a Suppression Subtraction Hybridisation (SSH) of B. ostreae infected- and non-infected haemocytes (Morga et al. 2011b). Among these, an EST showing similarity with Monosiga brevicolis HSP90 (e-value 5e-38) was selected for further characterization.

The open reading frame (ORF) of the HSP90 was completed using the SMART RACE cDNA Amplification kit (Clontech) on infected oyster cDNA synthesized from the SSH kit (Clontech). Sense and antisense primers were designed on the known sequence following manufacturer's instructions (Table 1). Once the total ORF was fully characterized by RACE PCR, the pair of primers HSP-F and HSP-R was designed to amplify the sequence (Table 1). PCR reactions were performed in a volume of $50 \mu \mathrm{l}$ containing PCR buffer (1X), $0.2 \mathrm{mM}$ nucleotides, $0.5 \mu \mathrm{M}$ of each primer, $7.5 \mathrm{U}$ of Taq polymerase (New England Biolabs) and $1 \mu \mathrm{l}$ of cDNA previously used for the RACE reactions. Thermal cycling was $94{ }^{\circ} \mathrm{C}$ for 5 min, 35 cycles of $94{ }^{\circ} \mathrm{C}$ for $1 \mathrm{~min}$ of denaturing, $58{ }^{\circ} \mathrm{C}$ for $1 \mathrm{~min}$ of annealing and $72{ }^{\circ} \mathrm{C}$ for $2.5 \mathrm{~min}$ of extension, followed 
by a $10 \mathrm{~min}$ final extension at $72{ }^{\circ} \mathrm{C}$. The resulting product was subcloned in several fragments using internal primers (Table 1). The pairs of primers utilized and each corresponding annealing temperature utilized were: HSP-F/156-R (58 $\left.{ }^{\circ} \mathrm{C}\right), 156-$ F/HSPseq-R $\left(60^{\circ} \mathrm{C}\right)$, HSP90-II3/HSPseq-R $\left(60^{\circ} \mathrm{C}\right)$ and HSP90-II3/HSP-R $\left(60^{\circ} \mathrm{C}\right)$. The total PCR product was diluted 1:10 in distilled water and used as template. The thermal cycle and the PCR mix were the same as described above.

Cloning and sequence analysis. PCR products were cloned using the TOPO TA Cloning kit (Invitrogen) and were transformed in Top 10F competent bacteria (Invitrogen). Inserts were analyzed by PCR using TOPO-F and TOPO-R primers (Table 1) before being sequenced from both ends with the same primers using a BigDye terminator Cycle Sequencing Ready Reaction kit and a 3100 Avant Genetic analyzer ABI Prism (Applied Biosystem). Raw chromatograms were analysed with Chromas 231 software (Technelysium). Sequence assembly, translation, multiple alignment and searches of homology were performed using ExPaSy tools (http://us.expasy.org/tools), and the GenBank database Blast algorithm (http://ncbi.nlm.nih.gov/blast/).

Phylogenetic analysis. Available HSP90 amino acid sequences were downloaded from GenBank and were included in phylogenetic analyses of the deduced BoHSP90 amino acid sequence obtained in the present study. Multiple sequence alignments were performed using Clustal W (Thompson et al. 1997). Phylogenetic analyses were conducted using the Maximum Likelihood method under MEGA5 software (Tamura et al. 2011). Statistical confidence of the inferred phylogenetic relationships was assessed by bootstraps of 1,000 replicates.

Genomic DNA extraction, status of samples regarding B. ostreae and HSP90 amplification. Genomic DNA was extracted from 25-mg gill tissues collected from infected and non- infected oysters or from purified B. ostreae using the QIAamp DNA 
Mini-kit (Qiagen). Infected and non- infected samples were identified by PCR using the BO-BOAS primer pair according to Cochennec et al. (2000). The same samples as well as DNA from purified parasites were tested by PCR using primers 156-F/156-R (Table 1) amplifying 154 bp of HSP90 gene. PCR reaction was performed in a volume of $50 \mu \mathrm{l}$ containing PCR buffer (1X), $0.2 \mathrm{mM}$ nucleotides, $1 \mu \mathrm{M}$ of each primer, $2.5 \mathrm{U}$ of Taq polymerase (New England Biolabs) and $1 \mu \mathrm{l}$ of genomic material containing $100 \mathrm{ng} / \mu \mathrm{l}$. Thermal cycling was at $94{ }^{\circ} \mathrm{C}$ for $5 \mathrm{~min}, 40$ cycles of $94{ }^{\circ} \mathrm{C}$ for $1 \mathrm{~min}$ of denaturing, 58 ${ }^{\circ} \mathrm{C}$ for $1 \mathrm{~min}$ of annealing and $72{ }^{\circ} \mathrm{C}$ for 1 min of extension, followed by 10 min of final extension at $72{ }^{\circ} \mathrm{C}$.

\section{In vitro exposure of haemocytes to $B$. ostreae preincubated with radicicol.}

The HSP90 inhibitor radicicol (SigmaAldrich), a macrocyclic antifungal drug, was suspended in $1 \mathrm{mM}$ dimethyl sulfoxide (DMSO). This parasite suspension was exposed for one hour at room temperature to increased concentrations (1, 5, 10 and $50 \mu \mathrm{M})$ radicicol diluted in FSW. Negative control parasites were exposed to FSW alone. The volume of DMSO used to dilute the highest concentration of radicicol was added to FSW and used as toxicity control (DMSO alone). Haemocytes were permitted to attach to the bottom of the 1.5-ml Eppendorf tube for $30 \mathrm{~min}$. Then, a B. ostreae suspension was added to them at a ratio of 5:1 (parasite: haemocyte). Contact experiments were conducted at room temperature for one hour. Approximately $100 \mu \mathrm{l}$ of the challenged haemocytes were then carefully resuspended by collecting with a pipette and cytocentrifuging at $100 \mathrm{~g}$ and $4{ }^{\circ} \mathrm{C}$ for $1 \mathrm{~min}$. Slides were fixed in ethanol and stained with Hemacolor (Merck) before light microscopic visualization. A total of 100 haemocytes containing at least one internalized parasite were counted. Results are presented by indexing the percentages of infection with the corresponding control. The 
experiment was repeated three times with a total of 10 oysters. Statistical differences were assessed using Students $t$-test.

\section{RESULTS}

Characterization of $\boldsymbol{B}$. ostreae HSP90. The HSP90 ORF was characterized by RACE-PCR and confirmed by PCR. It includes 2184 nucleotides encoding a protein of 728 amino acids (Fig. 1). This new gene was named BoHSP90 and deposited on the GenBank database with the accession number JX235927. The sequence did not contain signal peptide. The protein has a theoretical isoelectric point of 5.09 and a molecular weight of $83.46 \mathrm{KDa}$. Two characteristic domains were identified in BoHSP90 including an ATP binding domain (Fig. 1, single underline) and HSP90 domain (Fig. 1, double underline). The ATP binding domain is located between amino acids 37 and 182 and shows conserved residues involved in ATP binding and geldanamicyn (GA), a benzoquinone antibiotic, recognition. The HSP90 region starts at the residue 191 and contains a variable region of 68 residues with a high proportion of lysine and glutamic acid residues. The alignment of BoHSP90 with the 65 conserved amino acids comprising the 12 characteristic motifs of cytosolic HSP90 in other eukaryotes, including humans, are concordant with the idea that the HSP90 of B. ostreae is cytosolic. Among these, four motifs were exactly conserved in BoHSP90 and the remaining were one or two amino acids different in B. ostreae (Fig. 2). In total, 52 of the 65 conserved amino acids of cytosolic HSP90 perfectly aligned with the B. ostreae sequence. The MEEVD motif at the end of the C-terminal region, distinctive of cytosolic HSP90, was also conserved. However, the first glutamic acid residue in other eukaryotes was substituted by an aspartic acid residue in BoHSP90.

Phylogenetic analysis. BoHSP90 was compared with representatives of the cytosolic HSP90 subfamily. Results of similarity obtained after searching BlastP 
databases are shown in Table 2. BoHSP90 displayed 56\% identity with M. brevicolis (XP_001744222.1) and Hydra magnipapillata (XP_002165028.1). The phylogenetic tree obtained with complete HSP90 amino acid sequences (Fig. 3A) included a total of 14 sequences and 663 positions. BoHSP90 grouped with yeast in a sister group to other protist representatives of the groups Alveolata and Heterokonta. Metazoan representatives were used as outgroup. The sequences of near relatives of Bonamia ostreae were selected in the GeneBank to construct a more complete phylogenetic tree with 24 amino acid sequences (Fig. 3B). In this case the total residues analyzed were 256 since most of the sequences were incomplete and positions containing gaps were removed from the analysis. Alveolata and Heterokonta representatives grouped in the same branch although with a low support. Rhizaria resolved as a sister group to Alveolata and Heterokonta. Among Rhizaria representatives, B. ostreae grouped into Cercozoa with a bootstrap value of $47 \%$ with its closer relative Gymnophrys sp.

PCR amplification of BoHSP90 in gills of $\boldsymbol{O}$. edulis. Genomic DNA of gill tissues of $O$. edulis oysters were tested regarding the presence of $B$. ostreae using a PCR targeting the SSU rDNA fragment (Cochennec et al. 2000). The same samples were tested by PCR using 156-F/156-R primers (Table 1) that amplify BoHSP90 gene. Specific BoHSP90 primers yielded a product of 154 bp only in the oysters found positive using BO-BOAS (Fig. 4A, B) as well as in DNA from purified B. ostreae parasites (Fig. 4C).

Effect of radicicol on the phagocytosis of $\boldsymbol{B}$. ostreae. Purified parasites were preincubated with increased concentrations of radicicol before being used for contact experiments with $O$. edulis haemocytes. The internalization index was calculated for each radicicol concentration and oyster. The mean \pm standard deviation of 10 analyzed oysters are represented in Fig. 5. No differences were observed between controls and 
DMSO samples, indicating that the volume of DMSO used had no effect on haemocyte phagocytosis ability. The treatment of $B$. ostreae with $10 \mu \mathrm{M}$ and $50 \mu \mathrm{M}$ of radicicol significantly decreased the number of infected haemocytes compared to control ( $p$ value < 0.01). Haemocyte samples exposed to $B$. ostreae preincubated with $50 \mu \mathrm{M}$ radicicol had significantly fewer infected cells than samples exposed to 1,5 or $10 \mu \mathrm{M}$ radicicol. After $B$. ostreae incubation in $50 \mu \mathrm{M}$ radicicol, the number of infected haemocytes decreased more than $40 \%$ compared to controls.

\section{DISCUSSION}

Bonamia ostreae has been described as the causative agent of mass mortality events in natural stocks of the flat oyster O. edulis during last decades in France (Pichot et al. 1979). Although the immune response of the flat oyster to B. ostreae has been recently studied (Comesaña et al. 2012; Morga et al. 2009; Morga et al. 2011a), the information about the molecular basis that governs $B$. ostreae infection remains unknown. The impossibility of cultivating this parasitic protist and the difficulty in obtaining sufficient concentration of pure DNA hamper critical genomic analyses. In a previous study, some genes differentially expressed in B. ostreae infected haemocytes were identified using a SSH (Morga et al. 2011b). Among the identified ESTs, some transcripts were suspected to belong to the parasite. More particularly, one of these ESTs had homology with HSP90 from M. brevicolis and was used as a starting point of the present study.

HSP90 is a molecular chaperone expressed in all eukaryotic organisms and is divided into several subfamilies (Chen et al. 2006; Yahara et al. 1998). HSP90 is highly represented in most cells, reaching 1--2\% of total cytoplasmatic proteins (Csermely et al. 1998). HSP90 is involved in a variety of cell processes by maintaining the structure and integrity of “client” proteins (Csermely et al. 1998; Hao et al. 2010; Yahara et al. 
1998). Most of the information on protist HSP90 concerns those parasitic in mammals such as Plasmodium falciparum, Toxoplasma gondii and Theileria parva, (Ahn et al. 2003; Banumathy et al. 2003; Echeverria et al. 2010; Gerhards et al. 1994; Roy et al. 2012; Son et al. 2001). That the host environment is hostile for intracellular parasites and that HSP90 may help ameliorate this effect has been proposed (Csermely et al. 1998; Maresca and Carratù 1992; Neckers and Tatu, 2008). Furthermore, in $P$. falciparum the expression of HSP90 is up-regulated during infection and has been used as a marker for the physiological state of the parasite (Pallavi et al. 2010). Together, these data suggest a role for HSP90 in host-parasite interactions.

In the present work, HSP90 ORF was completed by RACE in cDNA of $B$. ostreae infected oysters. In order to confirm that the HSP90 gene belongs to B. ostreae, we tested the amplification of HSP90 in infected and non-infected oysters as well as in purified B. ostreae. We observed a positive correlation between HSP90 amplification and infected oysters detected by SSU rDNA amplification with BO-BOAS primers (Cochennec et al. 2000). A positive band of the expected size was also obtained in purified parasites. This fact leads us to verify that the HSP90 gene did not belong to the host.

Representatives of two subfamilies of HSP90 were described in protists, the cytosolic HSP90, and the HSP90 with a signal peptide that is found in the endoplasmic reticulum (Chen et al. 2006). BoHSP90 lacks signal peptide and is composed of 728 amino acids including specific residues of cytosolic HSP90 proteins. An exhaustive study based on the characterization of HSP90 across all kingdoms revealed the existence of 12 conserved motifs in cytosolic HSP90 (Chen et al. 2006). The presence of these 12 conserved motifs in BoHSP90 confirms that it belongs to the group of cytosolic HSP90. However, BoHSP90 showed some peculiarities. Among these 
conserved motifs, four were exactly conserved in BoHSP90 while the remaining motifs displayed one or two amino acid differences. Two of these amino acids differences were also observed in other protists included in our study (Fig. 2). For example, in B. ostreae, Trypanosoma cruzi and Dictyostelium discoideum, the second glutamic acid residue of the MEEVD motif, located at the C-terminal region, appeared to be substituted in those three species by glutamine, lysine, or aspartic acid, respectively. The MEEVD motif is involved in protein-protein interactions and mediates the recognition of tetratrico peptide repeat domains found in co-chaperones (D’Andrea and Regan 2003). Residues responsible for the ATPase activity that confers the chaperone function to HSP90, are located in the amino terminal domain (Prodromou et al. 1997a, b) although there are also ATP binding sites in the carboxy terminal domain (Garnier et al. 2002). A total of 17 residues of the amino terminal domain are involved in ATP binding (Dutta and Inouve 2000; Prodromou et al. 1997a, b) including the characteristic GxG pockets (Obermann et al. 1998). BoHSP90 presented 15 conserved residues of the ATP binding sites (Fig. 1). The valine and threonine residues at positions 172 and 174 in human HSP90 appeared to be replaced in BoHSP90 by isoleucine and aspartic acid, respectively; and the valine residue at position 189 is shifted one amino acid upstream in BoHSP90.

The N-terminal ATP binding sites are also recognized by the benzoquinone antibiotic geldanamycin (GA), the first described HSP90-specific inhibitor (Whitesell et al. 1994). The binding of GA to HSP90 disrupts the chaperone function by inhibiting the ATP binding that favours the conformational changes necessary for the folding of client proteins (Hao et al. 2010). Radicicol is a macrocyclic antifungal that shares the geldanamycin binding sites and also interferes with HSP90 functions (Schulte et al. 1998; Sharma et al. 1998). In order to investigate the involvement of HSP90 during 
haemocyte infection with $B$. ostreae we carried out in vitro experiments with parasites exposed to radicicol. The percentage of infected haemocytes drastically decreased after incubation of B. ostreae with this compound. To date, infective forms and entry mechanism of $B$. ostreae remain unknown. However, a study developed on haemocytes exposed to cytochalasin B revealed that the infection is a result of host phagocytosis and active parasite internalization (Chagot et al. 1992). Other studies have shown that the percent of infected haemocytes did not vary after exposure to live or dead B. ostreae (Morga et al. 2009). Therefore, the significant diminution of infected haemocytes observed in the current study suggests a possible role of radicicol in BoHSP90 inactivation. A similar inhibitory effect on cell invasion was previously observed in the intracellular parasite Eimeria tenella exposed to GA (Péroval et al. 2006). Moreover, intracellular growth and cell life cycle of other parasites like $T$. gondii and $P$. falciparum were also disturbed after treatment with GA (Ahn et al. 2003; Banumathy et al. 2003). Perhaps is not surprising that both radicicol and GA may interfere with the function of parasitic protist HSP90, since they share an ATP binding domain between amino acids 37 and 182 on this protein.

Because HSP90 is a highly conserved protein of eukaryotes and prokaryotes (Hao et al. 2010), it has been useful in understanding the evolution of all eukaryotes (Breglia et al. 2007; Chen et al. 2006; Parfrey et al. 2010), but most especially the phylogenetic position of dinoflagellates and alveolates (Fast et al. 2002; Harper et al. 2005; Hoppenrath and Leander 2010; Leander and Keeling 2004; Shalchian-Tabrizi et al. 2006). Previous studies using ribosomal DNA and actin have placed B. ostreae amongst Haplosporidia (Carnegie et al. 2000; Cochennec et al. 2000; López-Flores et al. 2007; Reece et al. 2004). Here, we first used complete HSP90 GeneBank sequences in an attempt to better define the placement of BoHSP90, but this strategy was not terribly 
informative and placed the parasite gene with yeasts in a distinct branch inside the protist cluster. We attribute this in part to the lack of complete HSP90 sequences of rhizarian representatives which are near relatives of B. ostreae (Burki et al. 2010; Harper et al. 2005; Yoon et al. 2008). When a second strategy using partial HSP90 sequences was employed (even though it reduced by half the number of informative positions in the phylogenetic matrix), BoHSP90 grouped with rhizarian representatives in a sister branch of the cluster of Alveolata and Heterokonta. Using multiprotein phylogenetic analyses (Burki et al. 2007; Hackett et al. 2007; Parfrey et al. 2010; Yoon et al. 2008), the relationship of Rhizaria to Alveoltata plus Heterokonta has been previously discussed and the term "Harosa” proposed to include them (Cavalier-Smith 2010; Cavalier-Smith and Chao 2012). In this study, BoHSP90 is resolved with moderate support (47\%) within the rhizarian cluster that includes haplosporidian members of the Cercozoa and very near to a species of Gymnophrys (Fig. 3B). These data are congruent with the earlier placement of haplosporidians within the group of Cercozoa (Cavalier-Smith 2002; Cavalier-Smith and Chao 2003). More importantly, these data for BoHSP90 describe for first time a complete cytosolic HSP90 gene in Rhizaria that can be used to extend hitherto less informative parts of the eukaryotic tree.

In the present work, the HSP90 of the Haplosporidia B. ostreae has been fully characterized, increasing the data available on protist parasite genes. We succeeded in amplifying the complete BoHSP90 from cDNA of infected oysters. Since obtaining genomic material on some protists is a difficult task, the use of infected samples could be a good alternative to increase parasite genomic data. BoHSP90 amplification was corroborated in a set of infected and non-infected oysters and also in purified parasites. Inhibitory studies with radicicol lead us to hypothesize that BoHSP90 could be involved 
in the infection process of $O$. edulis haemocytes. The characterization of the new $B$. ostreae HSP90 gene coding for a functional protein might have great interest for future studies on this species.

\section{ACKNOWLEDGEMENTS}

The Région of Poitou Charentes and IFREMER supported this research. The authors thank Raphael Brizard for technical assistance for the maintenance of oysters in IFREMER La Tremblade quarantine facilities.

\section{Literature Cited}

Ahn, H. J., Kim, S. \& Nam, H. W. 2003. Molecular cloning of the 82-kDa heat shock protein (HSP90) of Toxoplasma gondii associated with the entry into and growth in host cells. Biochem. Biophys. Res. Commun., 311:654--659.

Arzul, I., Langlade, A., Chollet, B., Robert, M., Ferrand, S., Omnes, E., Lerond, S., Couraleau, Y., Joly, J. P., François, C. \& Garcia, C. 2011. Can the protozoan parasite Bonamia ostreae infect larvae of flat oysters Ostrea edulis?. Vet. Parasitol., 179:69--76.

Banumathy, G., Singh, V., Pavithra, S. R. \& Tatu, U. 2003. Heat shock protein 90 function is essential for Plamodium falciparum growth in human erythrocytes. $J$. Biol. Chem., 278:18336--18345.

Breglia, S. A., Slamovits, C. H. \& Leander, B. S. 2007. Phylogeny of phagotrophic euglenids (Euglenozoa) as inferred from Hsp90 gene sequences. J. Eukaryot. Microbiol., 54: 86--92.

Bucke, D., Hepper, B., Key, D. \& Bannister, C. A. 1984. A report on Bonamia ostreae in Ostrea edulis in the UK. ICES Publ CM., 9:1--7. 
Burki, F., Shalchian-Tabrizi, K., Minge, M., Skjæveland, Å., Nikolaev, S. I., Jakobsen, K. S. \& Pawlowski, J. 2007. Phylogenomics reshuffles the eukaryotic supergroups. PLoS ONE, 2, art. 790.

Burki, F., Kudryavtsev, A., Matz, M. V., Aglyamova, G. V., Bulman, S., Fiers, M., Keeling, P. J. \& Pawlowski, J. 2010. Evolution of Rhizaria: new insights from phylogenomic analysis of uncultivated protists. BMC Evol. Biol., 10, art. 377.

Cáceres-Martínez, J., Robledo, J. A. F. \& Figueras, A. 1995. Presence of Bonamia and its relation to age, growth rates and gonadal development of the flat oyster, Ostrea edulis, in the Ria de Vigo, Galicia (NW Spain). Aquaculture, 130:15--23.

Carnegie, R. B., Barber, B. J., Culloty, S. C., Figueras, A. J. \& Distel, D. L. 2000. Development of a PCR assay for detection of the oyster pathogen Bonamia ostreae and support for its inclusion in the Haplosporidia. Dis. Aquat. Org., 42:199--206.

Cavalier-Smith, T. 2002. The phagotrophic origin of eukaryotes and phylogenetic classification of Protozoa. Int. J. Syst. Evol. Microbiol., 52:297--354.

Cavalier-Smith, T. 2010. Kingdoms Protozoa and Chromista and the eozoan root of the eukaryotic tree. Biol. Lett., 6:342--345.

Cavalier-Smith, T. \& Chao, E. E. 2003. Phylogeny and classification of phylum Cercozoa (Protozoa). Protist, 154:341--358.

Cavalier-Smith, T. \& Chao, E. E. 2012. Oxnerella micra sp.n. (Oxnerellidae fam. n.), a tiny naked Centrohelid, and the diversity and evolution of Heliozoa. Protist, 163:574--601.

Chagot, D., Boulo, V., Hervio, D., Mialhe, E., Bachere, E., Mourton, C. \& Grizel, H. 1992. Interactions between Bonamia ostreae (Protozoa:Acetospora) and 
hemocytes of Ostrea edulis and Crassostrea gigas (Molusca:Bivalvia): Entry mechanisms. J. Invertebr. Pathol., 59:241--249.

Chen, B., Zhong, D. \& Monteiro, A. 2006. Comparative genomics and evolution of the HSP90 family of genes across all kingdoms of organisms. BMC Genomics,7, art. 156.

Cochennec, N., Le Roux, F., Berthe, F. \& Gerard, A. 2000. Detection of Bonamia ostreae based on small subunit ribosomal probe. J. Invertebr. Pathol., 76:26--32.

Comesaña, P., Casas, S. M., Cao, A., Abollo, E., Arzul, I., Morga, B. \& Villalba, A. 2012. Comparison of haemocytic parameters among flat oyster Ostrea edulis stocks with different susceptibility to bonamiosis and the Pacific oyster Crassotrea gigas. J. Invertebr. Pathol., 109:274--286.

Comps, M., Tigé, G. \& Grizel, H. 1980. Etude ultrastructurale d'un protiste parasite de l’huitre Ostrea edulis L. C.R. Acad. Sc. Paris, Sér D, 290, p. 383--385.

Csermely, P., Schnaider, T., Sőti, C., Prohászka, Z. \& Nardai, G. 1998. The 90-kDa molecular chaperone family: structure, function and clinical applications: a comprehensive review. Pharmacol. Ther., 79:129--168.

Culloty, S. C. \& Mulcahy, M. F. 1996. Season-, age-, and sex-related variation in the prevalence of bonamiosis in flat oysters (Ostrea edulis L.) on the south coast of Ireland. Aquaculture, 144:53--63.

D’Andrea, L. D. \& Regan, L. 2003. TPR proteins: the versatile helix. Trends Biochem. Sci., 28:655--662.

Dutta, R. \& Inouve, M. 2000. GHKL, an emergent ATPase/kinase superfamily. Trends Biochem. Sci., 25:24--28.

Echeverria, P. C., Matrajt, M., Harb, O. S., Zappia, M. P., Costas, M. A., Roos, D. S., Dubremetz, J. F. \& Angel, S. O. 2005. Toxoplasma gondii Hsp90 is a potential 
drug target whose expression and subcellular localization are developmentally regulated. J. Mol. Biol., 350:723--734.

Echeverria, P. C., Figueras, M. J., Vogler, M., Kriehuber, T., de Miguel, N., Deng, B., Dalmasso, M. C., Matthews, D. E., Matrajt, M., Haslbeck, M., Buchner, J. \& Angel, S. O. 2010. The Hsp90 co-chaperone p23 of Toxoplasma gondii: Identification, functional analysis and dynamic interactome determination. Mol. Biochem. Parasitol., 172:129--140.

Elston, R. A., Farley, C. A. \& Kent, M. L. 1986. Occurrence and significance of bonamiasis in European flat oyster Ostrea edulis in North America. Dis. Aquat. Organ., 2:49--54.

Fast, N. M., Xue, L., Bingham, S. \& Keeling, P. J. 2002. Re-examining alveolate evolution using multiple protein molecular phylogenies. J. Eukaryot. Microbiol., 49:30--37.

Garnier, C., Lafitte, D., Tsvetkov, P. O., Barbier, P., Leclerc-Devin, J., Millot, J. M., Briand, C., Makarov, A. A., Catelli, M. G. \& Peyrot, V. 2002. Binding of ATP to Heat Shock Protein 90 Evidence for an ATP-binding site in the C-Terminal domain. J. Biol. Chem., 277:12208--12214.

Gerhards, J., Ebel, T., Dobbelaere, D., Morzaria, S. P., Musoke, A. J., Williams, R. O. \& Lipp, J. 1994. Sequence and expression of a 90-kilodalton heat-shock protein family member of Theileria parva. Mol. Biochem. Parasitol., 68:235--246.

Hackett, J. D., Yoon, H. S., Li, S., Reyes-Prieto, A., Rümmele, E. \& Bhattacharya, D. 2007. Phylogenomic analysis supports the monophyly of Cryptophytes and Haptophytes and the association of Rhizaria with Chromalveolates. Mol. Biol. Evol., 24:1702--1713. 
Hahn, J. S. 2009. The Hsp90 chaperone machinery: from structure to drug development. BMB Rep., 42:623--630.

Hao, H., Naomoto, Y., Bao, X., Watanabe, N., Sakurama, K., Noma, K., Motoki, T., Tomono, Y., Fukazawa, T., Shirakawa, Y., Yamatsuji, T., Matsuoka, J. \& Takaoka, M. 2010. HSP90 and its inhibitors (Review). Oncol. Rep., 23:1483-1492.

Harper, J. T., Waanders, E. \& Keeling, P. J. 2005. On the monophyly of chromalveolates using a six-protein phylogeny of eukaryotes. Int. J. Syst. Evol. Microbiol., 55:487--496.

Hoppenrath, M. \& Leander, B. S. 2010. Dinoflagellate phylogeny as inferred from Heat Shock Protein 90 and ribosomal gene sequences. PloS ONE, 5, art. 13220.

Leander, B. S. \& Keeling, P. J. 2004. Early evolutionary history of Dinoflagellates and Apicomplexans (Alveolata) as inferred from HSP90 and actin phylogenies. $J$. Phycol., 40:341--350.

López-Flores, I., Suárez-Santiago, V. N., Longet, D., Saulnier, D., Chollet, B. \& Arzul, I. 2007. Characterization of actin genes in Bonamia ostreae and their application to phylogeny of the Haplosporidia. Parasitology, 134:1941--1948.

Maresca, B. \& Carratù, L. 1992. The biology of the heat shock response in parasites. Parasitol. Today, 8:260--266.

McArdle, J. F., McKiernan, F., Foley, H. \& Jones, D. H. 1991.The current status of Bonamia disease in Ireland. Aquaculture, 93:273--278.

Mialhe, E., Bachère, E., Chagot, D. \& Grizel, H. 1988. Isolation and purification of the protozoan Bonamia ostreae (Pichot et al, 1980), a parasite affecting the flat oyster Ostrea edulis L. Aquaculture, 71:293--299. 
Montes, J. 1990. Development of Bonamia ostreae parasitosis of flat oyster, Ostrea edulis, from Galicia, northwest Spain. In: Perkins, F. O., Cheng, T. C. (ed.), Pathology in marine science. Academic Press, San Diego CA (USA). 223--227.

Montes, J., Anadon, R. \& Azevedo, C. 1994. A possible life cycle for Bonamia ostreae on the basis of electron microscopy studies. J. Invertebr. Pathol., 63:1--6.

Morga, B., Arzul, I., Chollet, B. \& Renault, T. 2009. Infection with the protozoan parasite Bonamia ostreae modifies in vitro haemocyte activity of flat oyster Ostrea edulis. Fish. Sellfish. Immunol., 26:836--482.

Morga, B., Renault, T., Faury, N., Chollet, B. \& Arzul I. 2011a. Cellular and molecular responses of haemocytes from Ostrea edulis during in vitro infection by the parasite Bonamia ostreae. Int. J. Parasitol., 41:755--764.

Morga, B., Arzul, I., Faury, N., Segarra, A., Chollet, B. \& Renault, T. 2011b. Molecular responses of Ostrea edulis haemocytes to an in vitro infection with Bonamia ostreae. Dev. Comp. Immunol., 35:323--333.

Narcisi, V., Arzul, I., Cargini, D., Mosca, F., Calzetta, A., Traversa, D., Robert, M., Joly, J. P., Chollet, B., Renault, T. \& Tiscar, P. G. 2010. Detection of Bonamia ostreae and B. exitiosa (Haplosporidia) in Ostrea edulis from the Adriatic Sea (Italy). Dis. Aquat. Organ., 89:79--85.

Neckers, L. \& Tatu, U. 2008. Molecular chaperones in pathogen virulence: Emerging new targets for therapy. Cell Host Microbe, 4:519--527.

Obermann, W. M., Sondermann, H., Russo, A. A., Pavletich, N. P. \& Hartl, F. U. 1998. In vivo function of Hsp90 is dependent of ATP binding and ATP hydrolysis. $J$. Cell. Biol., 143:901--910. 
Pallavi, R., Acharya, P., Chandran, S., Daily, J. P. \& Tatu, U. 2010. Chaperone expression profiles correlate with distinct physiological states of Plasmodium falciparum in malaria patients. Malar. J., 9, art. 236.

Parfrey, L. W., Grant, J., Tekle, Y. I., Lasek-Nesselquist, E., Morrison, H. G., Sogin, M. L., Patterson, D. J. \& Katz, L. A. 2010. Broadly sampled multigene analyses yield a well-resolved eukaryotic tree of life. Syst. Biol., 59:518--533.

Péroval, M., Péry, P. \& Labbé, M. 2006. The heat shock protein 90 of Eimeria tenella is essential for invasion of host cell and schizont growth. Int. J. Parasitol., 36:1205--1215.

Pichot, Y., Comps, M., Tige, G., Grizel, H. \& Rabouin, M. A. 1979. Research on Bonamia ostreae gen. n., sp. n., a new parasite of the flat oyster Ostrea edulis L. Rev. Trav. Inst. Pêches Marit., 43:131--140.

Pratt, W. B. \& Toft, D. O. 2003. Regulation of signaling protein function and trafficking by the hsp90/hsp70-based chaperone machinery. Exp. Biol. Med., 228:111--113.

Prodromou, C., Roe, S. M., Piper, P. W. \& Pearl, L. H. 1997a. A molecular clamp in the crystal structure of the N-terminal domain of the yeast Hsp90 chaperone. Nat. Struct. Biol., 4:477--482.

Prodromou, C., Roe, S. M., O’Brien, R., Ladbury, J. E., Piper, P. W. \& Pearl, L. H. 1997b. Identification and structural characterization of the ATP/ADP-binding site in the Hsp90 molecular chaperone. Cell, 90:65--75.

Reece, K. S., Siddall, M. E., Stokes, N. A. \& Burreson, E. M. 2004. Molecular phylogeny of the haplosporidia based on two independent gene sequences. $J$. Parasitol., 90:1111--1122.

Robert, M., Garcia, C., Chollet, B., Lopez-Flores, I., Ferrand, S., François, C., Joly, J. P. \& Arzul, I. 2009. Molecular detection and quantification of the protozoan 
Bonamia ostreae in the flat oyster, Ostrea edulis. Mol. Cell Probes, 23:264-271.

Roy, N., Nageshan, R. K., Ranade, S. \& Tatu, U. 2012. Heat shock protein 90 from neglected protozoan parasites. Biochim. Biophys. Acta, 1823:707--711.

Schulte, T. W., Akinaga, S., Soga, A., Sullivan, W., Stensgard, B., Toft, D. \& Neckers, L. M. 1998. Antibiotic radicicol binds to the N-terminal domain of HSP90 and shares important biologic activities with geldanamycin. Cell Stress Chaperones, 3:100--108.

Shalchian-Tabrizi, K., Minge, M. A., Cavalier-Smith, T., Nedreklepp, J. M., Klaveness, D. \& Jakobsen, K. S. 2006.Combined heat shock protein 90 and ribosomal RNA sequence phylogeny supports multiple replacements of dinoflagellates plastids. J. Eukaryot. Microbiol., 53:217--224.

Sharma, S. V., Agatsuma, T. \& Nakano, H. 1998.Targeting of the protein chaperone, HSP90, by the transformation suppressing agent, radicicol. Oncogene, 16:2639-2645.

Son, E. S. \& Nam, H. W. 2001. Detection and characterization of excretory/secretory proteins from Toxoplasma gondii by monoclonal antibodies. Korean $J$. Parasitol., 39:49--56.

Tamura, K., Peterson, D., Peterson, N., Stecher, G., Nei, M. \& Kumar, S. 2011. MEGA5: Molecular evolutionary genetics analysis using máximum likelihood, evolutionary distance, and maximum parsimony methods. Mol. Biol. Evol., 28:2731--2739.

Thompson, J. D., Gibson, T. J., Plewniak, F., Jeanmougin, F. \& Higgins, D. G. 1997. The Clustal X windows interface: flexible strategies for multiple sequence alignment aided by quality tools. Nucl. Acids Res., 25:4876--4882. 
Van Banning, P. 1985. Control of Bonamia in Dutch oyster culture. In: Ellis, A. E. (ed.), Fish and shellfish pathology. Plymouth Academic Press, London. 393-396.

Van Banning, P. 1990. The life cycle of the oyster pathogen Bonamia ostreae with a presumptive phase in the ovarian tissue of the European flat oyster, Ostrea edulis. Aquaculture, 84:189--192.

Whitesell, L., Mimnaugh, E. G., De Costa, B., Myers, C. E. \& Neckers, L. M. 1994. Inhibition of heat shock protein HSP90-pp60v-src heteroprotein complex formation by benzoquinone ansamycins: essential role for stress proteins in oncogenic transformation. Proc. Natl. Acad. Sci. USA, 91:8324--8328.

Wiesgigl, M. \& Clos, J. 2001. Heat shock protein 90 homeostasis controls stage differentiation in Leishmania donovani. Mol. Biol. Cell, 12:3307--3316.

Yahara, I., Minami, Y. \& Miyata, Y. 1998. The 90-kDa stress protein, Hsp90, is a novel molecular chaperone. Ann. N. Y. Acad. Sci., 851:54--60.

Yoon, H. S., Grant, J., Tekle, Y. I., Wu, M., Chaon, B. C., Cole, J. C., Logsdon, Jr. J. M., Patterson, D. J., Bhattacharya, D. \& Katz, L. A. 2008. Broadly sampled multigene trees of eukaryotes. BMC Evol. Biol.,8, art. 14.

\section{FIGURE LEGEND}

Fig. 1: Complete ORF and deduced amino acid sequence of BoHSP90. The initial and stop codons are marked in grey. Conserved domains appear underlined: ATP binding domain is simple underlined, the HSP90 domain is double underlined. Residues of the variable region are indicated in grey. Residues involved in ATP binding are marked in black.

Fig. 2: Multiple alignment of HSP90 amino acid sequence of Bonamia ostreae with other representatives of the cytosolic HSP90 subfamily. Variable region is 
enclosed by arrows. Conserved motifs of cytosolic HSP90 are marked in grey and the MEEVD motif at the C-terminal end is indicated in black. The conserved GxG boxes are also pointed out in the alignment. Sequences of HSP90 were obtained from the GeneBank Database: Mus musculus (BAE27553.1), Homo sapiens (NP_005339.3), Perkinsus marinus (XP_002775585.1), Toxoplasma gondii (XP_002368278.1), Babesia bovis (XP_001611554.1), Achlya ambisexualis (AAM90674.1), Candida albicans (XP_721353.1). The following consensus symbols were used in the alignment: $\left(^{*}\right)$ residues identical in all sequences, (:) conserved substitutions and (.) semi-conserved substitutions.

Fig. 3: Maximum Likelihood tree of the amino acid sequences showing the phylogenetic relationships among HSP90 complete amino acid sequences (A) and partial amino acid sequences (B). Bootstrap of 1,000 repetitions. Sequences of HSP90 were obtained from the GeneBank Database: Theileria parva (AAA30132.1), Plasmodium falciparum (AAA66179.1), Saccharomyces cerevisiae (AAA02743.1), Hydra magnipapillata (XP_002165028.1), Dugesia japonica (ACM91724.1), Crassostrea gigas (ABS18268.1), Philodina roseola (ACC43981.1), Microplitis mediator (ABV55506.1), Phytopythium helicoides (BAI94555.1), Phytophthora phasoli (ABU99530.1), Pseudopedinella elastica (ACM78547.1), Nannochloropsis gaditana (ACM78546.1), Thraustochytrium aureum (ACM78551.1), Spumella uniguttata (AAR27540.1), Prorocentrum micans (AAR27546.1), Massisteria marina (ADK90079.1), Larcopyle butschlii (BAK61732.1), Thaumatomonas sp. (ABJ80964.1), Bigelowiella natans (XP_001712819.1), Gymnnophrys sp. (ADK90077.1).

Fig. 4: A. Detection of HSP90 with specific primers 156-F/156-R. Lanes 1 and 30, 100 bp DNA ladder (New England BioLabs), lanes 2--28, DNA from gills of infected and non-infected oysters. Negative control (non-infected oyster) in lane 29. B. 
Detection of the SSU rDNA with BO-BOAS primers in the same samples. C. Detection of HSP90 in DNA from purified Bonamia ostreae (lane 2). Positive and negative controls are DNA of infected and non-infected oysters (lanes 3, 4) and no-DNA control (lane 5). Lanes 1 and 6 DNA ladder (SmartLadder, Eurogentec).

Fig. 5: Bonamia ostreae internalization index after incubation with increased concentrations of radicicol. (*) Significant differences between values indicated with lines ( $p$ value $<0.01, \mathrm{n}=10)$. 


\section{Figure 1}

1 tcggggattgcgtaaaattagctttactaaataaatggttgcagttaatgaatctgttaaa 62 - M V A V N E S V K

63 ggagagcgetacgctttttccgcggacatcaacaatctgctcggcttgataatcaacacg

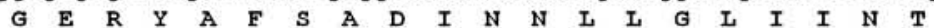

123 ttctattcgaacaacgatgtcttcctcagggaactcatctccaattcgtctgacgcaata

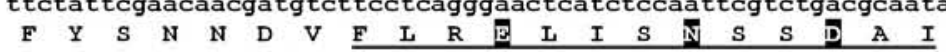

183 gacaagataaagttcaagtcgettacagactcttcggtgctcggcgatgaaacagaatt $\begin{array}{llllllllllllllllllll}\mathrm{D} & \mathrm{K} & \mathrm{I} & \mathrm{K} & \mathbf{F} & \mathrm{K} & \mathbf{S} & \mathrm{L} & \mathbf{T} & \mathrm{D} & \mathrm{S} & \mathrm{S} & \mathrm{V} & \mathrm{L} & \mathrm{G} & \mathrm{D} & \mathrm{E} & \mathbf{T} & \mathbf{E} & \mathbf{F}\end{array}$

243 aaatccaaatcgtccetaacaaggaagccaaaacgctcactatccgtgacaacggaatt $\begin{array}{lllllllllllllllllllll}K & I & Q & I & V & P & N & K & & \text { D } & A & K & T & L & T & I & R & D & N & G & I\end{array}$

303 ggcatgacgaaagacgaaatggtcaaaaatctaggaacaatcgccacgtccggaactaa

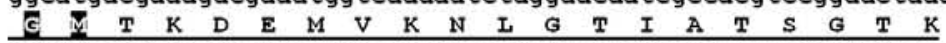

363 getttcatggacgctattcaagcgggcgccgatattcaaatgatcggccaattcggtgtc $\begin{array}{llllllllllllllllllll}A & F & M & D & A & I & Q & A & G & A & D & I & Q & M & I & G & Q & F & G & V\end{array}$

423 ggattctattccgcgttcctcgtttcagatctcgtcgaagtcagatcaaagagtaacgac

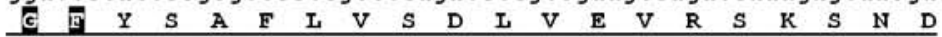

483 ggcaagcaatttgtctggacctccacggcttcgggcgaattccacatttatgacgactcc \begin{tabular}{llllllllllllllllllll}
$G$ & $K$ & $Q$ & $F$ & $V$ & $W$ & $T$ & $S$ & $T$ & $A$ & $S$ & $G$ & $E$ & $F$ & $H$ & $I$ & $Y$ & $D$ & $D$ & $S$ \\
\hline
\end{tabular}

$543 \frac{G}{\text { gaaacgagcaccagctcaaacgeggcaccgaaatcgttttgcacttgaaagacggccag }}$

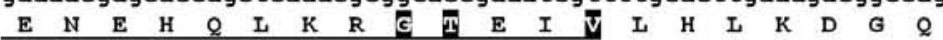

603 acggagtacctcgaagaaaacaagatcaaagagatcgtgcacaaacacagcgaattcgtt

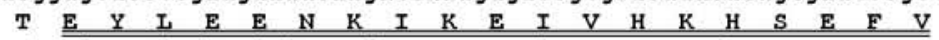

663 ggtcctcagatcctcctctggacttcgaaagaggtcgaaaaagaagtcagcgacgacgaa

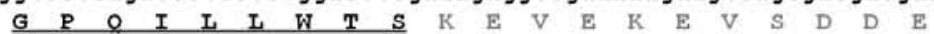

723 gacgagaagaaagaagacgagaagaaggactctgataagaaaaaagatgaagactcggac

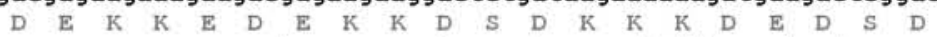

783 gaaaagaaagaagacaaatcggacgaagtcgeggtgaaagatgtttcagatgctceggag

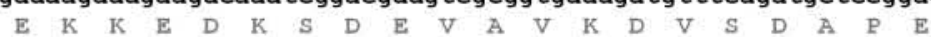

843 ccgaagaaggaaaagaaaaag tcactgaaatcg tcgaagagttcactcgcgtcaacagc

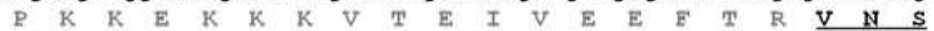

903 accaaacctctgtgggegatgaagecggaagacatcaagaaggaagagtacacegcgttc

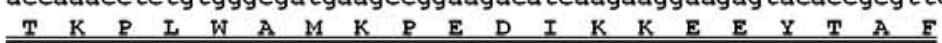

963 tacaagtccatctcgaacgactgggaagaaccgttggcttacaagcacttccacgtcgaa

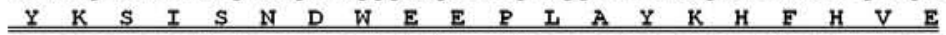

1023 gggcaagtcgagttcactgtcattctcttcgttccgaagagaatgcetttcgatctcttc $\begin{array}{llllllllllllllllllll}G & O & V & E & F & T & V & I & I & F & V & P & K & R & M & P & F & D & I & F\end{array}$

1083 aataacaataaggatccaagcaacatcaagcttttcgtccgtcgtgttctgatcaacgaa $\begin{array}{llllllllllllllllllll}N & N & N & K & D & P & S & N & I & K & I & F & V & R & R & V & L & I & N & E\end{array}$

1143 caagcgaaagagctttgtcctgaatatttgagcttcatcaaaggagttgttgacagtgaa $\begin{array}{llllllllllllllllllll}O & A & K & E & I & C & P & E & Y & I & S & E & I & K & G & V & V & D & S & E\end{array}$

1203 gaatgccactcaatatttcaagagagaccttgcagaagaacacaataatgaaagtgatc

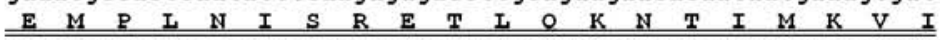

1263 cgcaacaacatcgccaaaaaagccatcgaactcttcttcgaaatctctgaagacaaagag $\begin{array}{llllllllllllllllllll}R & N & N & I & A & K & K & A & I & E & I & E & F & E & I & S & E & D & K & E\end{array}$

1323 ctttcaagaccttctacaagaacttttccaaaaacatcaaatatggcatccacgaagat

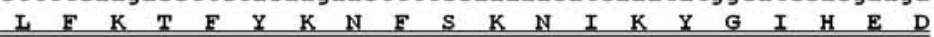

1383 tcgacgaaccgcaagaagctcgcagatctcattcgettcaactccacctccagtgggaag

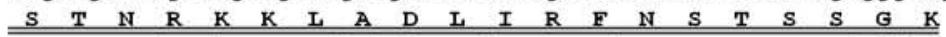

1443 gaacaacggtcgctcaaagattatgtcgagtegatgcetgaacaccaaaagatatttac 1502 $\begin{array}{llllllllllllllllllll}E & O & R & S & I & K & D & Y & V & E & S & M & P & E & H & 0 & K & D & I & Y\end{array}$

1503 tacatcaccggcgactcccaagaatcgctggagaacatgccettcctcgaagtcctcaaa 1562

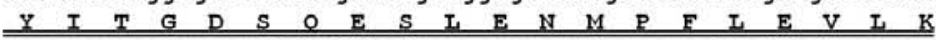

1563 aagaaaagctcgaggttctttttatgaccgacccgatcgacgagtactttgtgcagcag 1622

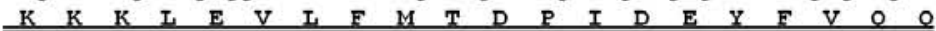

1623 atgagcgaatacgaaggacacaagttggtgagcgtcaccaaagaaggactcgagttgccg 1682

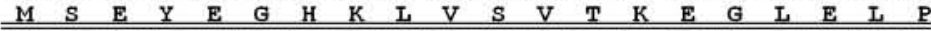

1683 caaacagacgaagagaagaaaaagcacgaagaggtgaagaaggagttcgagcecttctgc $\quad 1742$

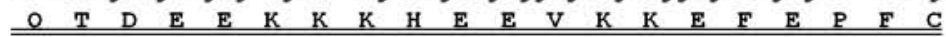

1743 aaacgcgtgaaggagatccttggagegcgegtcgagaaagtegaggtgagcaatcgtatg 1802

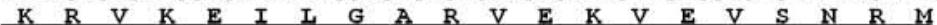

1803 accgagtcgcegtgctacatttccaccggcaattcgggtggagttccaggatggggeag $\quad 1862$

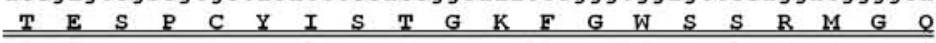

1863 atcatgaagaaccaagegetgcgegacaccaccttcagctcccacatggecgccaaaaag 1922 $\begin{array}{llllllllllllllllllll}I & M & K & N & O & A & I & R & D & T & T & F & S & S & H & M & A & A & K & K\end{array}$

1923 atcttggagatcaacccgcatcacgccgtcgtggaggagatggcgagacgcctgaaggaa 1982

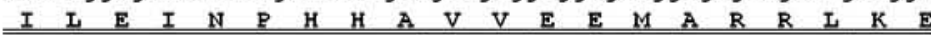

1983 aacgtgaacgacgcgatggcgaaggatctggtgtggctcatatacgaaacggctgtgctc 2042

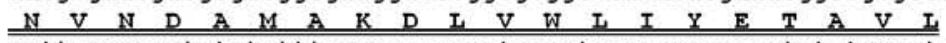

2043 acttcgggeggtctctctttggagaacceggtcgagtacgcaggcagaatctataagctg 2102

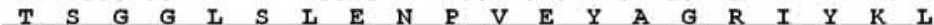

2103 acgcgtcttggactggggatcgtcaccgagaaggacgctggcgaagatttgccggacctg

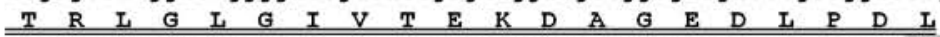

2163 gaacctgctgatggagagaaggagaacgaagctacggcagagatggaagatgtcgattga \begin{tabular}{llllllllllllllllllll}
$E$ & $P$ & $A$ & $D$ & $G$ & $E$ & $K$ & $E$ & $N$ & $E$ & $A$ & $T$ & $A$ & $E$ & $M$ & $E$ & $D$ & $V$ & $D$ \\
\hline
\end{tabular}

2223 ttagtaaagcgtgtcgcgacaaaaaaaaaaaaaaaaaaaaaaaaaagtactctgc

2283 gttgataccactgcttgccctatagtgagtcgtattagaagccgaattctgcagatatcc

2343 atcacactggcggcegctcgagcatgcatctagagggccca 


\section{Figure 2}

Mus musculus Perkinsus marinus Toxoplasma gonula Achlya ambls Candida albicans Bonamía ostreae

Mus musculus Homo sapiens Toxkinsus marinus Babesia bovis Achlya ambisexuat Candida albicans
Bonamía ostreae

Mus musculus Homo sapiens Toxoplasma gondi. Babesia bovis Achlya ambisexual Candida albicarts

Mus musculus Homo sapiens Perkinsus marinus Toxoplasma gondi: Babesia bovis Achlya ambisexuat1s candtaa albicans

Mus musculus Homo sapiens Perkinsus marinus Toxoplasma gond: Babesia bovis Candida albicans. Bonamia ostrese

Mus musculus Homo sapiens Toxoplasma gondit Babesia bovis Achlya ambisexuatis candida albicans Bonamia ostreae

Mus musculus Homo sapiens Torkinsus marinus Babesia bovis Achlya ambisexuat Candida albicans
Bonamia ostreae MPEETQTQDQPMEEEEVETFAFQAEIAQLMSLIINTFYSNKEIFLRELISNSSDALDKIRYESLTDPSKLDSGKELHTNLIPSKQDRTLTIVDTG GXG MPEETQTQDQPMEEEEVETFAFQAEIAQLMSLI INTFYSNKEIFLRELISNSSDALDKIRYESLTDPSKLDSGKELHINLI PNKQDRTLTIVDTGIGMTKADLINNLGTIAKSGTKAFME MADTERFARTA

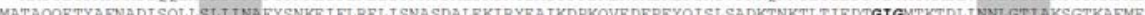

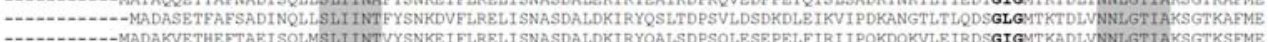
-MADAKETHEFTAEI SQLMSLI INTVYSNKEI FLRELISNASDALDKIRYQALSD DSQLESEPELFIRII PQKDQKVLEIRDSGIGMTKADLVMLGGIAKSGTKSEME ALQAGADI BMIGQFGVGFYSAYLVAEKVTVITKHNDDEQYANESSATGGSETVRTDTGEPMG---RGTKVILHLKEDQTEYLEERRTKEIVKKHSQFIGYPITLFVEKERDKEVSDDEAEE ALQAGGDI SMIGQFGVGFYSAYLVADVRVVVSKSNDDDQYIWESAAGGSFSVTKDTEFADGHIKRGTKVILYLKEDQTEFLEERRLKDLVKKHSQFIGFPIELYVEKSTEKEV TDSEDEE

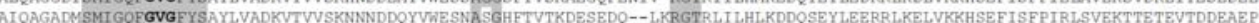
AL QAGADI SMI GOEGVGFYSAYLVADRVTVHSKHNDDEQHVWESAAGGSFTVSRDTNSEP--IKRGTRIVLKLKEDMLEYLEERKLKDLVKKHSEFIGFPIRLYVEKTTEKEVTDDEDDE ALSAGADVSMI GQFGVGFY LFLVADHVQVISKHNDDEQYVWESNAGGKFTVTLDETNER-- LGRGTMLRLFLKEDQLEYLEEKRTKEVVKKHSEFVAYPIQLVVTKEVEKEVPETEEED AIQAGADIOMI GQFGVGFYSAFLVSDLVEVRSKSNDGKQFWWTSTASGEFHIYDDSENEHQ-LKRGYEIVLHLKDGQTEYLEENKIKEIVHKHSEFVGPQILLWTSKEVEKEVSDDEDEK

$$
\leftarrow
$$

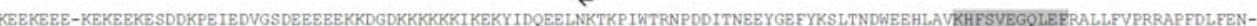
KEDKEEE-KEKEEKESEDKPE IEDVGSDEEEE-KKDGDKKKKKKIKEKY IDQEELNKTKP IWTRNPDDTTNERYGEFYKSLTNDWERDHLAVKHFSVEGQLEFRALLFVPRRAPFDLFEN-

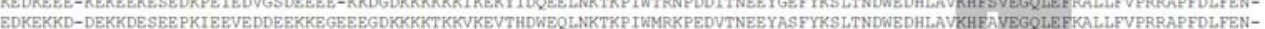
KPAEDAE-EKKEBGEEEKKEEGAE---------KKKKTKKVKEVVVEYEQLNKOKPLWMRKPEDVTWEEYCAFYKSLTNDWEDPLAVKHFSVEGQLEFKALLFLPKRAPFDLFETTEAESKP-EEKITDVTEEEEEKEKEAEK----DGEEKTEKKKRKVTNVTREWEMLNKOKP IWMRLPTEVTNEEYASFYKNLSNDWEDHLAVKHFSVEGQLEFKAILFVPKRAPFDMFENEEEGDDK-PKIEEVKDDED--1.---KKKKTKKIKEVSHEWDLLNSQKP IWMRKPEDVTHEEYAAFYKSLTNDWEEHAAVKHFSVEGQLEFKACLFTPKRAPFDMFEGG

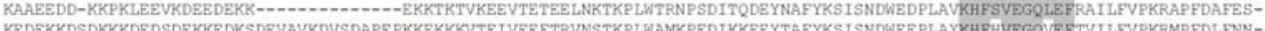

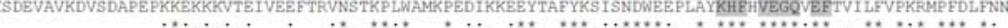

-RKKKNNI KLYVRRVFIMDNCEELIPEYLNFIRGVVDSEDLPINI SREMLOQSKI LKVIRKNLVKKCL.ELFTELAEDK-ENYKKFYEQFSKNIKLGIHEDSQNRKKLSELLLRYYTSASGD

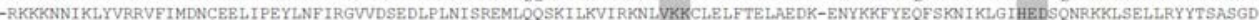
-TKKRNNIKLTVRRVFITDDCEELMPDWLSFIKGVVDSEDLPLNISRETLOQNKILRVIKKNLVKKCLQLFEEMATEKPDDYKIFYEOFSKNIKLGIHEDSTNREKIAELLLRFKSSKSGE -RKKRNNVRLYVRRVFIMDDCEDLTPEWLNFVRGVDSEDLP LNISRESLQQNKI LKVIKKNLVKKCLEMFQELEEKK-EDYTKFYEQF SKNLKLGIHEDTSNRNKIAELLRFHTSKSGD -RKKKNNIKLYVRRVFIMDDCDELIPEWLGFVKGVVDSEDLPLNISREVLQRNK ILKVIRKNLVKKCLELFSELTEKK-EDFKKFYEQFSKNLLKLGI HEDNTNRNKI SELLRYETSKSGD

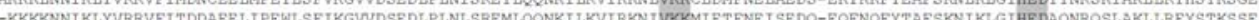

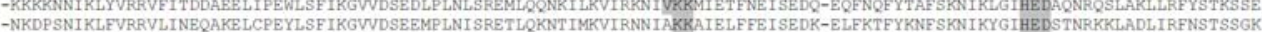

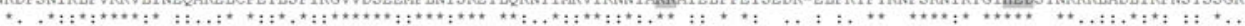

EMVSLKDYCTRMKENOKHTYFITGETKDQVANSAFVERLRKHGLEVIYMIEP IDEXCVQQLKEFEGKTLVSVTKEG-LELPEDEEEKRKQEEKKTKFENLCKIMKDILEKKVEKVVVSNR EMVSLKDYCTRMKENOKHIYYITGETKDQVANSAFVERLRKHGLEVIYMIE P DDEYCVQQLKEFEGKTLVSVTKEG-LELFEDEEEKKKQEEKKTKFENLCKIMKDILEKKVEKVVVNR

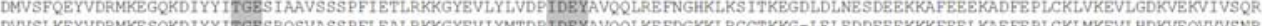
DMTSLDDYISRMPENOPGIYYVTGESKKSVENSPFI KKL KKKGYEVL FMVDP IDEYAVOQMKDYEGKKLICATKEG-LDINNSEDEKKAFEEAKAATEGLCKLMKEVLDDKVEKVOTSNR

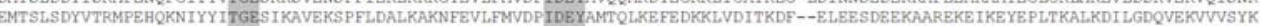
EQRSLKDYVESMPEHQKDTYYITGDSQESLENMPFLEVLKKKKLEVLFMTDP IDEYFVQQMSEYEGHKLVSVTKEG-LELPQT DEEKKKHEEVKKEFEPFCKRVKEILGARVEKVEVSNR

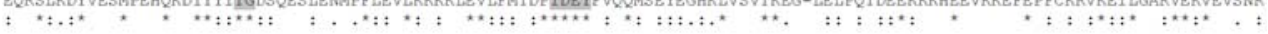
LVTSPCCIVTSTYGWTANMERTMKAQALRDNSTMGYMAAKKHLEINPDHSIIETLRQKAEAD-KNDKSVKDLVILLYYTALIISSG-FSLEDPQTHANRIYRMIKLGLLIDEDDPTVDDTS

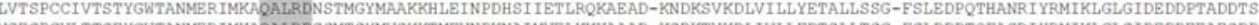

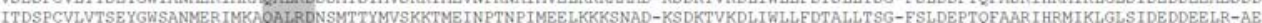

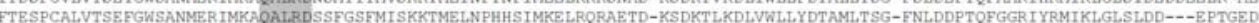

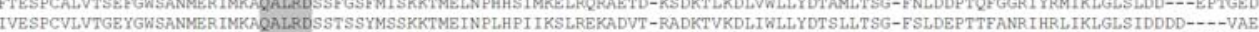
LVDAPAAIRTGQFGWSANMERIMKAQALRDTTTMSSYMSSKKTFEISPSSPIIKELKKKVETDGAEDKTVKDLTTLLFDTALLTSG-FTLDEPSNFAHRINRLIALGLNIDDDSEETAVEP MTESPCYISTGKFGWSSRMQIMKNQALRDTTFSSHMAAKKILEINPHHAVVEEMARRLKEN-VNDAMAKDLVWLIYYTAVLTSGGLSLENPVEYAGRIYKLTRLGLGIVTEKDAGEDLP AAVTEEMP PLEGDDDT ANTEEMPPLEGDDDTSE EDLPPLEEVEG-A VDLPPLDEVVVDE

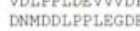
DAMDDLPPLEGDEG DLEPADGEKENEAT 
Figure 3

A

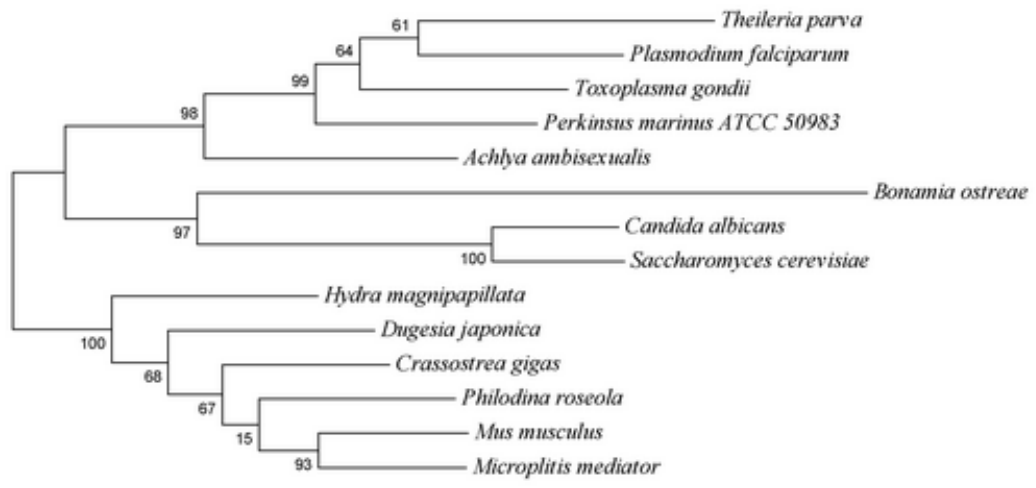

0.05

B

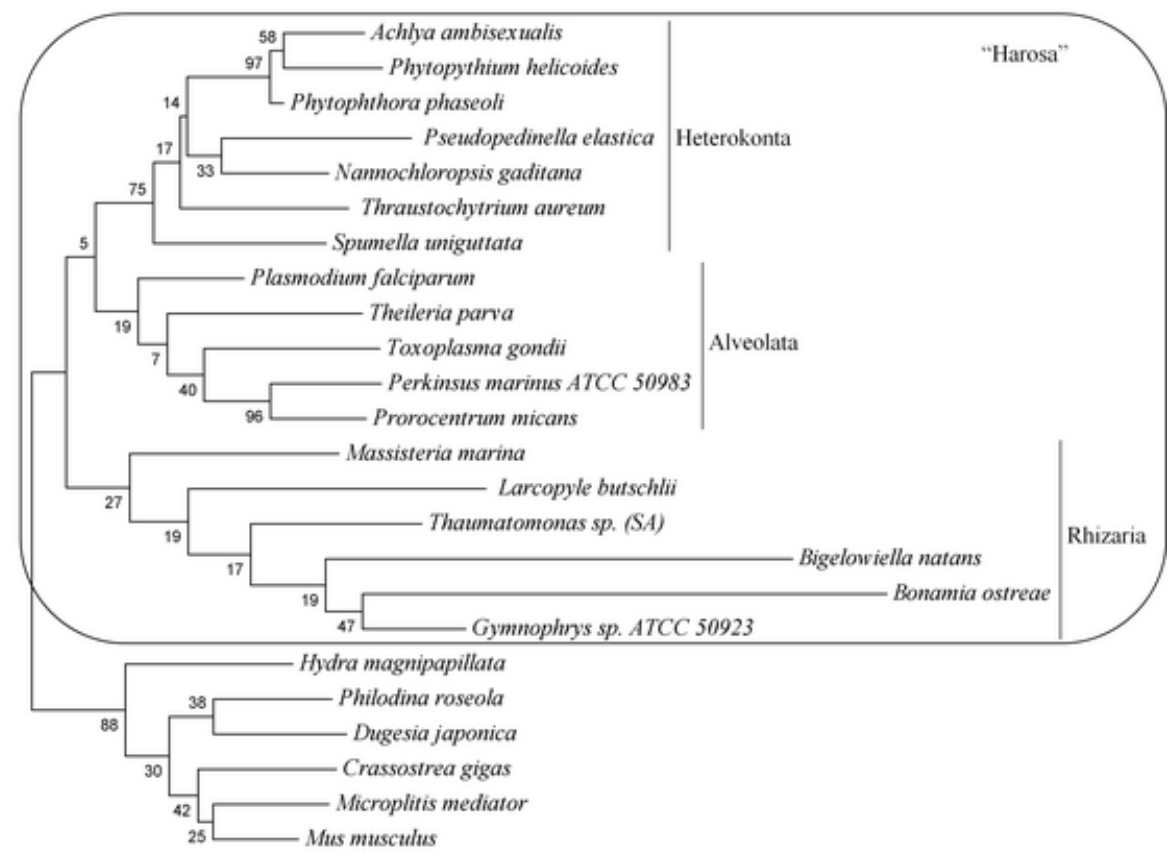

$\stackrel{\longmapsto}{0.05}$ 
Figure 4

A

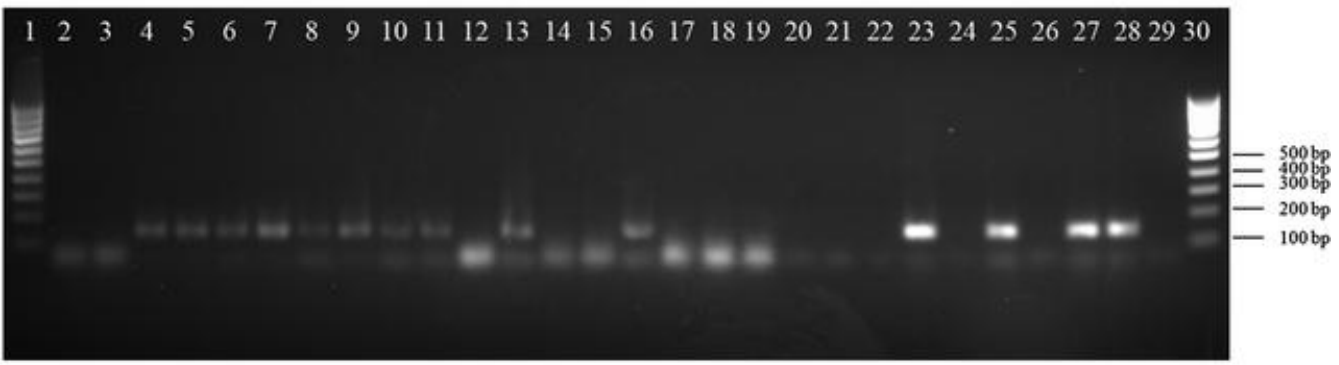

B

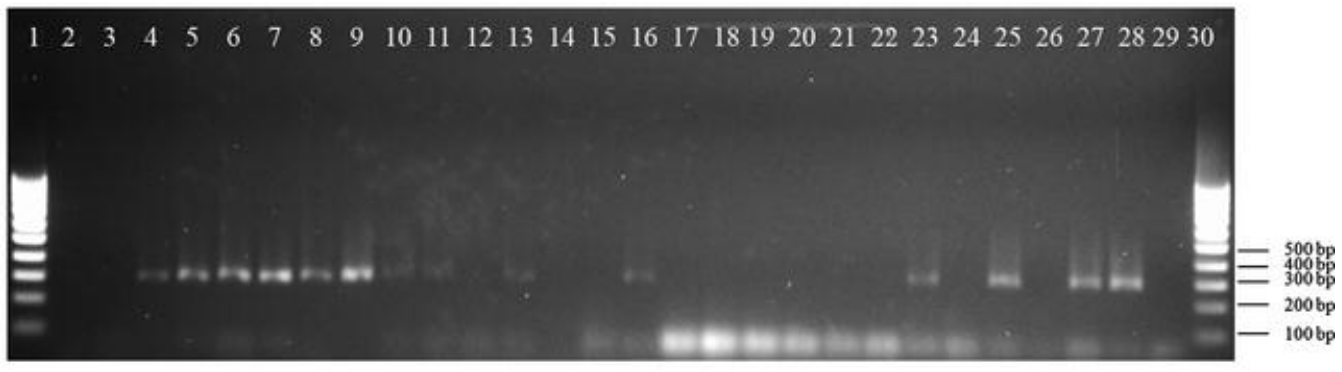

C

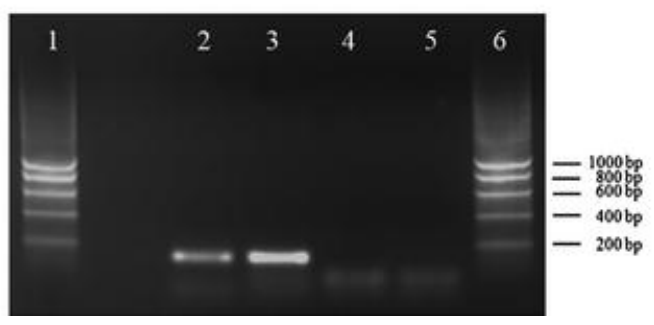

Figure 5

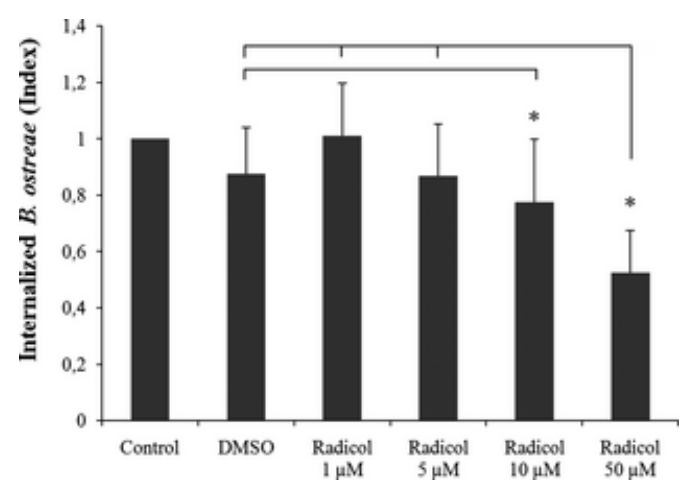

